Demiryolu Mühendisliği

Temmuz 2021

Sayı:14, Sayfa: 110-121

Araştırma Makalesi
Railway Engineering

July 2021

Issue:14, Page: 110-121

Research Article

doi: 10.47072/demiryolu.932732

http://dergipark.org.tr/demiryolu

e-ISSN: 2687-2463, ISSN: 2149-1607

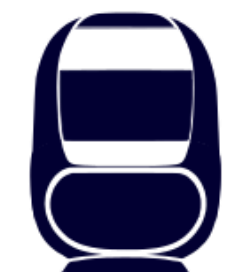

\title{
İstanbul Metrolarında Yolcu Konforunun Arttırılması: Sinyalizasyon Sistemi ile Otomatik Anons Kontrol Uygulamasi
}

\author{
Emre ÇEKEREK ${ }^{* 1}$ (D), Mehmet DEMIR ${ }^{2}$ D \\ 1-2 Kocaeli Üniversitesi, Fen Bilimleri Enstitüsü, Elektronik ve Haberleşme Mühendisliği \\ ${ }^{2}$ Ístanbul Büyükşehir Belediyesi Metro İstanbul AŞ \\ *emrecekerek@gmail.com
}

(Alınış/Received: 04.05.2021, Kabul/Accepted: 29.06.2021, Yayımlama/Published: 31.07.2021)

Öz: Yer altı metro hatlarında, işletmeci firmalar yolcuların seyahat sürelerini azaltmak, dakik ulaşım kolaylığı sağlamak, güvenli ve ekonomik taşımacılık gibi birçok alanda olumlu çözümler geliştirerek hizmet etmektedir. Sunulan bu olumlu gelişmeler neticesinde metro hatlarını kullananların sayısında her geçen yıl artış gözlenmektedir. Yolcu sayısındaki bu artı̧ konfor hizmetinde her geçen gün yeni gelişmeler olmasına neden olmaktadır. Bu kapsamdan yola çıkarak M5 Üsküdar-Ümraniye-Çekmeköy sürücüsüz metro hattında yoğun yolcu saatleri veya dışında yaşanan trenden inen ve binen yolcu arasındaki kargaşanın önlenmesinden ve son zamanlarda yaşanılan Covid-19 salgın hastalığındaki sosyal mesafenin korunması hususunda yapılan çalışmadan bahsedilmektedir. Çalışma sonucunda trenin perona gelmesine 1 dakika kala peron bölgesinde ve araç içerisindeki yolculara, sinyalizasyon ve SCADA sistemi yazılım entegrasyonuyla otomatik anons yaptırılip inenlere öncelik verilmesi ve sosyal mesafeye dikkat edilmesi konusunda bilgilendirici anonslar yaptırılması sağlanmaktadır.

Anahtar kelimeler: Sürücüsüz metro, Otomatik anons, Covid-19, Sinyalizasyon, SCADA

\section{Increasing Passenger Comfort in Istanbul Metro: Automatic Announcement Control Application with Signalization System}

\begin{abstract}
Operating companies on subway lines serve by developing positive solutions in many areas such as reducing travel times of passengers, providing punctual transportation convenience, and safe and economical transportation. As a result of these positive developments, the number of users using subway lines is increasing every year. This increase in the number of passengers provides new developments every day in comfort service. Based on this context, in this study will be a focus on the R\&D work, which in order to protect the concept of social distance that came into our lives with the Covid-19 outbreak, will be carried out the prevent the chaos, that happens at peak and off-peak hours that passengers get on and off the train in M5 driverless subway line. At the end of the study, one minute before the train arrives on the platform; the passengers in the platform area and in the vehicle will be automatically announced with signaling and SCADA system integration. Moreover, informative announcements will be made about "the priority" and "pay attention to social distance".
\end{abstract}

Keywords: Driverless subway, Automatic announcement, Covid-19, Signalling, SCADA

\section{Giriş}

Gelişmiş şehirlerde hızlı nüfus artışıyla birlikte ulaşım sektöründe gözle görülür seviyede problemler ortaya çıkmaktadır. Nitekim ulaşımdaki bu problemler şehir idarecilerinin farklı çözümler aramalarına neden olmaktadır. Toplu taşıma ulaşımında otobüs, metrobüs ve minibüsler akla ilk gelen taşıtlar olarak göze çarpmaktadır. Fakat modern şehircilik kültürünü ilke edinen belediyeler daha hızlı, konforlu, verimli, ekonomik ve dakik ulaşım kolaylığı sağlayan raylı sistemlere yönelmektedir. Metro, tramvay, füniküler ve banliyö trenleri raylı sistemlere örnek olarak gösterilmektedir. Son dönemlerde raylı sistemlerde yolcu taşıma kullanımının 
yaygınlaşmasıyla her geçen gün kullanıcı sayısını da arttırmaktadır [1]. Bu artış sonucunda sunulan hizmetlerde işletmeci firma tarafından her geçen gün geliştirilmektedir.

Raylı sistem sektörü kendi içerisinde birçok alanda faaliyet gösterir. Elektrik, elektronik, haberleşme, elektromekanik, demiryolu, inşaat, işletme ve sinyalizasyon sistemleri gibi geniş bir alanda faaliyetlerini gerçekleştirir. Gelişen teknolojiyle birlikte sistem fonksiyonelliği genişleyebilmektedir. Mekanik sistemlerden, sürücülü metro hatlarına, oradan da artık sürücüsüz metro hatlarına gelişim hızla artmaktadır. Sürücüsüz metro hatlarında en önemli faktör ise sinyalizasyon sistemleridir.

Demiryollarında sinyalizasyon sistemleri; trenlerde ve hat boyunca uygulanan elektromekanik kontrol ve haberleşme sayesinde ulaşımın hızlı, güvenli ve daha kısa sürelerde yapılmasını sağlayan oldukça karmaşık bir kontrol mekanizmasıdır [2]. Sinyalizasyon ve tren kontrol ürünleri, demiryollarının gelişmiş performansına en çok katkıda bulunan bileşenler arasındadır. Son on yılda demiryolu endüstrisi, şu anda piyasada bulunan teknolojilerden ve yeniliklerden yararlanarak sinyalizasyon sistemlerini iyileştirmek için önemli araştırma ve geliştirme çabalarına yatırım yapmışlardır [3]. M5 Üsküdar-Ümraniye-Çekmeköy sürücüsüz metro hattında sinyalizasyon sistemi olarak Fransa merkezli enerji ve taşımacılık alanında faaliyet gösteren Alstom firması bünyesindeki Bombardier Transportation firmasına ait CITYFLO 650 sistemi kullanılmaktadır. CITYFLO 650, yeni veya mevcut toplu taşıma uygulamaları için Bombardier Transportation tarafından geliştirilen son teknoloji ürünü bir İletişim Tabanlı Tren Kontrolü (Communications Based Train Control - CBTC) hareketli blok çözümüdür.

CITYFLO 650 sinyalizasyon sistemi, farklı özellik ve işlevsellikler sağlayan birçok alt sistemden oluşur [4];

- Araç Otomatik Tren Kontrolü (Vehicle Automatic Train Control - VATC)

- Bölgesel Otomatik Tren Kontrolü (Region Automatic Train Control - RATC)

- Veri Haberleşme Sistemi (Data Communication System - DCS)

- A $\breve{g}$ Telsiz Sistemi (Network Radio System - NRS)

- Otomatik Tren Denetimi (Automatic Train Supervision - ATS)

- Nesne Kontrolörü ve Yolboyu Sinyal Ekipmanları

- Peron Ayırıc1 Kapı Sistemi (PAKS)

Sinyalizasyon sistemlerinin yanı sıra yer altı metro hatlarında faaliyet gösteren diğer bir önemli sistem ise SCADA sistemidir. SCADA (Supervisory Control and Data Acquisition - Merkezi Denetleme Kontrol ve Veri Toplama) sistemi geniş bir alana yayılmış ekipmanların haberleşme protokolleri kullanılarak bir veya birden fazla merkezden yazılım aracılı̆̆ıyla; izlenmesini, denetlenmesini, kontrol edilmesini, alarm durumları takibinin anlık ve geçmiş zaman birimlerine göre saklanmasını sağlayan sistemlere verilen genel isimdir. SCADA sisteminde üç ana bileşen vardır. Bu bileşenler; merkezde bulunan ana istasyon, Uzak Terminal Birimleri (Remote Terminal Unit - RTU) ve ana istasyon ile RTU' lar arasındaki haberleşme ortamlarıdır [5]. SCADA sistemi endüstride birçok alanda kullanılmaktadır. Bunlar; nükleer tesisler, enerji santralleri, otomotiv endüstrisi, doğalgaz çevrim tesisleri, demir çelik endüstrisi, reaktör güç kontrol tesisleri ve rüzgâr türbinleri gibi sektörlerdir.

$\mathrm{Bu}$ çalışmada, M5 Üsküdar-Ümraniye-Çekmeköy sürücüsüz metro hattında yoğun yolcu saatlerinde veya dışında yaşanan trenden inen ve binen yolcu arasındaki kargaşanın önlenmesinden ve son zamanlarda yaşamış olduğumuz Covid-19 salgın hastalığındaki sosyal mesafenin korunması hususunda yapılan şirket içi çalışmadan bahsedilmektedir. Sinyalizasyon ve SCADA sistemleri arasında bir haberleşme modeli oluşturulmuş ve iki sistem arasındaki haberleşmenin yapılmasını sağlayan adres değerleri ise belirlenmiştir. Böylece trenden inen 
yolculara öncelik verilmesi ve sosyal mesafeye dikkat edilmesi konusunda bilgilendirici anonslar duyurulması sağlanmaktadır. Geliştirilen model ile Metro İstanbul AŞ’ nin yolculara sunmuş olduğu konforlu hizmet seviyesi arttırılması hedeflenmektedir.

\section{Sinyalizasyon ve SCADA Sistemi}

Sinyalizasyon sistemine bağlı tüm cihazların haberleşmesi Veri İletim Sistemi (Data Transmission System-DTS) adı verilen ağ sistemi üzerinden gerçekleşmektedir. Dışarıdan sisteme herhangi bir veri akışı olmamaktadır. Bu şekilde olması sistemin güvenilirlik seviyesini arttırmaktadır. DTS; istasyon odalarında bulunan merkezi kontrol kabinlerindeki cihazların ve yol boyunda yer alan cihazlar ile haberleşmesini sağlamaktadır. Sistemin emniyet ve güvenilirlik gerekliliklerini korumak için, DTS ağı farklı amaçlar için kullanılması engellenmiştir. Harici alt sistemler ile haberleşme güvenlik duvarı (firewall) cihazlarıyla yapılmaktadır. Yeni nesil güvenlik servisleriyle güvenlik duvarı cihazları, boyutu ne olursa olsun, dışarıdan gelen saldırı ve tehditlere karşı sistemi korumaktadır. SCADA, yolcu bilgilendirme ve saat sistemlerine ait veri bilgilerini güvenlik duvarı üzerinden sinyalizasyon sistemiyle aktarılmaktadır [6].

CITYFLO 650, hareketli blok teknolojisinde tasarlanmıştır. Tren konumu kendisi tarafından sürekli olarak hesaplanmaktadır ve daha sonra telsiz ağı üzerinden yol boyu ekipmanına bildirilmektedir. Bu şekilde, yol boyu ekipmanı tren konum bilgisini sürekli olarak güncellemekte ve en yakın engele kadar her bir tren için hareket yetkisi sınırını dinamik olarak oluşturmaktadır. Hesaplama, konum belirsizliği için bir emniyet payı içerir ve bu emniyet payı tren uzunluğuna eklenerek genelde 'footprint' (ayak izi) olarak adlandırılan tanımı oluşturur. Trenler, hareketli blok prensibinden yararlanarak daima minimum emniyetli mesafede çalışabilmektedir. $\mathrm{Bu}$ şekilde, trenler arasındaki sefer aralığı (Headway) azalmakta ve taşıma kapasitesi artmaktadır [4].

CITYFLO 650 alt sistemi ve SCADA sistemi ile haberleşmeyi sağlayan ATS sistemi, tüm cihazlardan aldığ 1 bilgiyi EBIScreen 1500 yazılımı aracılığıyla operatörün sisteme ait verileri izleme, denetleme, kontrol etme ve sahaya komut gönderme gibi işlevlerini yerine getirme imkânı verir. Trenlerin hat üzerindeki anlık konumları, istasyonlarda bulunan peron ayırıcı kapılarının durumları, her iki yönlü trafik akışını sağlayan makasların konumları, otomatik tren düzenlemesi (Automatic Train Regulation - ATR), trenlere elle veya otomatik rota verilmesi, RATC cihazlarının takibini sağlayan cihazların sağlık durumlarının yapıldığı ekrandır. Sistem kendisine bağlı tüm ekipmanlar ile sürekli olarak iletişim kuran bir kullanıcı/sunucu mimarisiyle tasarlanmıştır. Aktif ve sıcak yedekli modda çalışan iki sunucusu ve çok sayıda kullanıcısı mevcuttur. Tren kontrol sunucuları ATS sisteminin bir alt parçasıdır. Sahadan aldığı bilgileri derleyip kullanıcıların hattı kontrol etmelerini ve denetlemesini sağlar. Aktif ve sıcak yedekli modda çalışan iki sunucusu ve bunlara bağlı veri depolamasını yapan yine aktif ve sıcak yedekli modda çalışan veri tabanı sunucuları bulunmaktadır.

Sinyalizasyon sistemi kendi iç haberleşmesi dışında harici sistemlerle haberleşme yapabilmektedir. Harici sistemlerden alınan bilgiler tren kontrol sunucusu üzerinden sistemde işlenir hale getirilir ve denetlenir. Sunuculara harici olarak bağlanan sistemler ise Saat (Network Time Protocol - NTP), YBS (Yolcu Bilgilendirme Sistemi), SCADA, VIM ve Araç Yıkama (Car Wash) sistemidir. Bu çalışmada kullanılan sistem ise SCADA sistemidir. Veri haberleşmesi programlanabilir lojik kontrolörü (Programmable Logic Controller - PLC) üzerinden gerçekleştirilmelidir. ATS PLC' ye alınan veri ise doğrudan sisteme bağlanmaz. Güvenlik duvarı cihazı ile denetim üst safhaya çıkarılır ve sisteme dâhil edilir (Şekil 1). SCADA ile ATS PLC arasında kullanılan haberleşme protokolü ise ethernet tabanlı olan Modbus TCP/IP' dir. SCADA ise sunucu olarak görev yapar. ATS PLC' ler ana ve yedek kontrol merkezinde aktif ve sıcak yedekli modda iki adet olmak üzere Tren Kontrol (Train Control - TC) kabininde bulunmaktadır. $\mathrm{Bu}$ projede kullanılan PLC markası ise Schneider firmasının üretmiş olduğu Modicon Premium serisine aittir. 


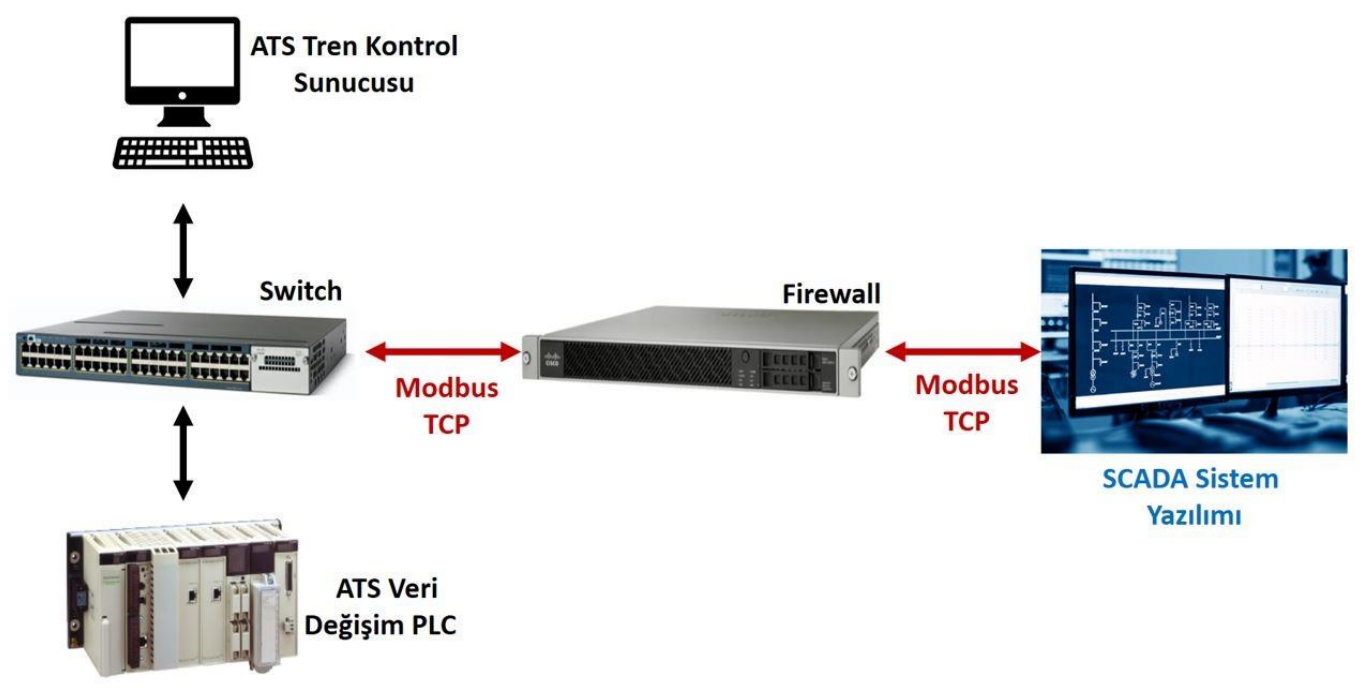

Şekil 1. SCADA sistemi - ATS PLC haberleşme mimarisi

\subsection{Haberleșme protokolü}

ATS ve harici alt sistemler arasındaki veri aktarımı, TCP/IP (Transmission Control Protocol / Internet Protocol - İletim Kontrol Protokolü / İnternet Protokolü) üzerindeki uygulama katmanı protokolü olan MODBUS protokolü üzerinde gerçekleşmektedir. Otomasyon cihazlarının denetim ve kontrol amaçlı tasarlanan kullanımı basit olan bir protokoldür. Klasik internet ağ topolojisine göre haberleşme sunan bu protokol standart olarak kullanılan internet kartları ile 100 Mbps hız ile veri aktarımı yapar. TCP/IP protokolü ile çok sayıda bağlantı yapılabilir. Sunucu/istemci cihazlar aralarında bağlantı kurulur ve veri aktarımı gerçekleşir. Herhangi bir cihaz istemci veya sunucu olabileceği gibi sistemde birçok sunucu veya istemci olabilir [7].

Modbus protokolü İstemci-Sunucu uygulamasında kullanılır. Aynı ağa bağlı 247 cihaz arasında haberleşmeyi sağlayabilmektedir. CITYFLO 650 sinyal sisteminde kullanılan Modbus yapılandırması harici arayüzler için Modbus İstemci, ATS Veri Değişim PLC'si ise Modbus Sunucu olarak yapılandırılmıştır.

\section{Uygulama}

Sistemin tasarımına üç başlık halinde değinilmektedir. Bunlar; sinyalizasyon, SCADA ve anons yapılandırmalarında kullanılan işlem adımlarıdır.

\subsection{Sinyalizasyon yaptlandırmast}

Veri saklama (kayıt tutucu): Kayıt tutucu, PLC içerisinde 16 bit değer taşıyan bir konumdur. Modbus adreslemesinde, bir kayıt tutucu, 4xxxxx gibi 4 ile başlayan beş veya altı bir basamaklı sayıdır. Buradaki 4, adresin "kayıt tutucu" olduğunu belirtir ve geriye kalan sayılar asıl kayıt tutucu adresini gösterir. Gönderilen bilgi kendisine bağlı cihazda dört farklı tablo halinde saklanır. Saklama işlemi iki ayrı tablo halinde olmaktadır. Bunlar kapalı/açık durum değerlerini gösteren Çıkışlar, diğer ikisi de sayısal değerleri gösteren Register veri tipleridir. Çıkış ve kayıt tabloların her biri salt okunur ve okuma-yazma özelliğine sahiptir. Her bir tablo 9999 değere sahiptir. Her bir çıkış 1 bitlik değere karşılık gelir ve 0000 ile 270E arasında veri adres bloğuna tanımlanmıştır. Her bir Register ise 16 bit yani 2 byte' dır. Bu da 1 kelimeye karşllık gelmektedir. Örneğin ilk veri saklama, 40001 sayıs1, 0000 veri adres bloğuna sahiptir 
Tablo 1. Veri saklama tanımları

\begin{tabular}{ccc}
\hline Veri Saklama No & Modbus Adresleri & Bilgi Açılaması \\
\hline 400100 & 66 & ATS Genel Sistem Durumu \\
400300 & 166 & Ray/Hat Güç/Enerji Durumu Bilgisi \\
400500 & 365 & Havalandırma Bölge Durum Bilgisi \\
400700 & 565 & Arıza Alarmları (Ekipman) Bilgisi \\
410000 & 8555 & İstasyon Durum Bilgisi \\
420000 & 16999 & Peron Durumu ve Arıza Alarmları (Peronlar) Bilgisi \\
430000 & 28655 & Tren Durumu ve Arıza Alarmları (Trenler) Bilgisi
\end{tabular}

ATS - PLC konfigürasyonu: Ana ve yedek kontrol merkezinde ikişer adet olmak üzere toplamda 4 adet ATS Tren Kontrol Sunucusu vardır. Bu sunucuların bulunduğu kabinde ise sicak yedekli olarak yapılandırılmış ikişer adette ATS Veri Değişim PLC' si bulunmaktadır. Her iki kontrol merkezindeki PLC' ler yalnızca bulundukları mahaldeki sunucular ile bağlantı sağlamaktadır. Ana kontrol merkezinin kullanımını herhangi bir nedenle sonlandırmak gerektiğinde (herhangi bir acil durumda, örneğin yangın, arıza vb.), o kontrol merkezindeki sunucular halen çalışmaya devam ediyorsa ve iş istasyonları ana kontrol merkezindeki sunuculara bağlıysa, yedek kontrol merkezindeki bir iş istasyonundan bir değişim komutu vermek mümkündür. Dışarıdan sisteme dâhil olmak isteyen kullanıcılar her iki kontrol merkezindeki PLC' leri kullanabilir lakin sadece aktif kontrol merkezi hangisi ise o PLC' lerden veri okuyup yazılabilmektedir [8].

ATS - genel sistem durumu: Trenler, sisteme dinamik olarak eklenebilir ve kaldırılabilmektedir (Tabloda 400110 - 400130 arasındaki satırlar ekleme yapılan bölümlerdir). Kayıt 420000’ den başlanması ile hâlihazırda iletişim halinde olan tüm trenler listelenir (Tablo 3). Bu eşleştirme (mapping), harici arayüz yüklenicilerine tüm tren durum etiketlerini taramadan trenleri verilerine bakmak için referans sağlar [8].

Tablo 2. ATS genel sistem durumu

\begin{tabular}{|c|c|c|c|}
\hline Adres & MODBUS Adresi & Açıklama & Yorum \\
\hline 400100 & 66 & Ay $(1-12)$ & Mevcut ATS Tarih / Zaman bilgisi \\
\hline 400101 & 67 & Gün (1-31) & Mevcut ATS Tarih / Zaman bilgisi \\
\hline 400102 & 68 & Yil & Mevcut ATS Tarih / Zaman bilgisi \\
\hline 400103 & 69 & Saat $(0-23)$ & Mevcut ATS Tarih / Zaman bilgisi \\
\hline 400104 & 70 & Dakika (0-59) & Mevcut ATS Tarih / Zaman bilgisi \\
\hline 400105 & 71 & Saniye (0-59) & Mevcut ATS Tarih / Zaman bilgisi \\
\hline 400106 & 72 & SCADA Durumu & SCADA her saniye güncellenir \\
\hline 400107 & 73 & COM Durumu PIS & COM PIS her saniye güncellenir \\
\hline 400108 & 74 & $\begin{array}{c}\text { PLC Sağlık } \\
\text { Durumu Kaydı }\end{array}$ & $\begin{array}{l}\text { Bit masklı PLC Sağlık Durumu } \\
\text { Bit } 0-\text { MCC PLC1 (1 = aktif }) \\
\text { Bit } 2-\text { RCC PLC2 (1 = aktif })\end{array}$ \\
\hline 400109 & 75 & Tren Sayımı & VATC kontrollü trenlerin sayıs1 \\
\hline 400110 & 76 & $\begin{array}{c}\text { VATC Tren ID @ } \\
\text { Dizin } 1\end{array}$ & $\begin{array}{c}\text { Tren ID lookup' a tren durum verisi } \\
\text { Tren @ dizin } 1 \text { için tren verisi başlangiç adresi } \\
430000 \\
0=\text { tren yok @ dizin } 1\end{array}$ \\
\hline 400111 & 77 & $\begin{array}{c}\text { VATC Tren ID @ } \\
\text { Dizin } 2\end{array}$ & $\begin{array}{c}\text { Tren ID lookup' a tren durum verisi } \\
\text { Tren @ dizin } 2 \text { için tren verisi başlangıç adresi } \\
430030 \\
0=\text { tren yok @ dizin } 2\end{array}$ \\
\hline
\end{tabular}




\begin{tabular}{|c|c|c|c|}
\hline$\cdots$ & $\cdots$ & $\begin{array}{c}\text { VATCTren ID@ } \\
\text { Dizin } n\end{array}$ & $\begin{array}{c}\text { Tren ID lookup' a tren durum verisi } \\
\text { Tren @ dizin n için tren verisi başlangiç adresi } \\
430000+\left((\mathrm{n}-1)^{*} 30\right) \\
0=\text { tren yok @ dizin } \mathrm{n}\end{array}$ \\
\hline 400130 & 96 & $\begin{array}{c}\text { VATC Tren ID @ } \\
\text { Dizin } 21\end{array}$ & $\begin{array}{c}\text { Tren ID lookup' a tren durum verisi } \\
\text { Tren @ dizin } 21 \text { için tren verisi başlang1ç } \\
\text { adresi } 430600 \\
0=\text { tren yok @ dizin } 21\end{array}$ \\
\hline
\end{tabular}

ATS - peron bilgi durumu ve adresleri: Peron Bilgi Durumu, harici alt sistemlere temel peron bilgilerini sağlamak için tasarlanmıştır. Peron bilgilendirmesi, gelen trenlerin kalkış zamanı gibi peron durumu hakkındaki bilgiler ve operatörler tarafından ayarlanmış bilgileri içerir. Tren varış ve kalkış zamanları, belirli bir zamana kadar olan 2 tren için sağlanmalıdır. Bu zaman genellikle bir saate kadar olmalıdır. Peron durum bilgisi, peron kimliği (platform ID) ile dizinlenecektir. Peron Kimlik numarası 011 için (Üsküdar) başlangıç kaydı 420000’ dir. Diğer istasyonlar 50' şer artışla sıralanırlar [8].

Tablo 3. Peron bilgisi durumu

\begin{tabular}{|c|c|c|c|}
\hline Adres & $\begin{array}{l}\text { MODBUS } \\
\text { Address }\end{array}$ & Açıklama & Yorum \\
\hline 420000 & 14999 & Peron ID & $\begin{array}{l}\text { CBTC haritasında belirtildiği üzere } \\
\text { peron kimliği (ID 011) }\end{array}$ \\
\hline 420001 & 15000 & İstasyon Kontrol Seviyesi & $\mathrm{MCC}=1, \mathrm{RCC}=2, \mathrm{SM}=3$ \\
\hline 420002 & 15001 & Peron Tut & Peron tut $=1$ \\
\hline 420003 & 15002 & Peron Atla & Peron atla $=1$ \\
\hline 420004 & 15003 & Peron Servis dışı & Peron servis diş $1=1$ \\
\hline 420008 & 15007 & 1. VATC tren ID & ----------- \\
\hline 420009 & 15008 & 1. Tren Durma Göstergesi & Tren istasyonda duruyor $=1$ \\
\hline 420010 & 15009 & 1. Tren Varış Saati & Trenin gelişine saniyeler var \\
\hline 420011 & 15010 & 1. Tren Kalkış Saati & Trenin kalkışına saniyeler var \\
\hline 420012 & 15011 & 1. Tren varış yeri & $\begin{array}{c}\text { Hiçbir varış yeri kümesi }=0 \text {, Geçerli } \\
\text { değerler }=1-65535\end{array}$ \\
\hline 420017 & 15016 & 2. VATC tren ID & -------- \\
\hline 420018 & 15017 & 2. Tren Duruş Göstergesi & Tren istasyonda duruyor $=1$ \\
\hline 420019 & 15018 & 2. Tren Varış Saati & Trenin gelişine saniyeler var \\
\hline 420020 & 15019 & 2. Tren Kalkış Saati & Trenin kalkışına saniyeler var \\
\hline 420021 & 15020 & 2. Tren varış yeri & $\begin{array}{c}\text { Hiçbir varış yeri kümesi = } 0 \text {, } \\
\text { Geçerli değerler }=1-65535\end{array}$ \\
\hline
\end{tabular}


Tablo 4. Peron adresleri durumu

\begin{tabular}{ccccc}
\hline İst. ID & Peron ID & İst. Adı & Veri Adresi & MODBUS Adresi \\
\hline 01 & 011 & Üsküdar & 420000 & 12999 \\
01 & 012 & Üsküdar & 420050 & 13049 \\
02 & 021 & Fistıkağaci & 420100 & 13099 \\
02 & 022 & Fistikağacı & 420150 & 13149 \\
03 & 031 & Bağlarbaş1 & 420200 & 13199 \\
03 & 032 & Bağlarbaş1 & 420250 & 13249 \\
04 & 041 & Altunizade & 420300 & 13299 \\
04 & 042 & Altunizade & 420350 & 13349 \\
05 & 051 & Kisılı & 420400 & 13399 \\
05 & 052 & Kisıklı & 420450 & 13449 \\
06 & 061 & Bulgurlu & 420500 & 13499 \\
06 & 062 & Bulgurlu & 420550 & 20549 \\
07 & 071 & Ümraniye & 420600 & 20599 \\
07 & 072 & Ümraniye & 420650 & 13649 \\
08 & 081 & Çarş1 & 420700 & 13699 \\
08 & 082 & Çarş1 & 420750 & 13749 \\
09 & 091 & Yamanevler & 420800 & 13849 \\
09 & 092 & Yamanevler & 420850 & 13899 \\
10 & 101 & Çakmak & 420900 & 13949 \\
10 & 102 & Çakmak & 420950 & 13999 \\
11 & 111 & Ihlamurkuyu & 421000 & 14049 \\
11 & 112 & Ihlamurkuyu & 421050 & 14099 \\
12 & 121 & Altınşehir & 421100 & 14149 \\
12 & 122 & Altısşehir & 421150 & 14199 \\
13 & 131 & Lise & 421200 & 14249 \\
13 & 132 & Lise & 421250 & 14299 \\
14 & 141 & Dudullu & 421300 & 14349 \\
14 & 142 & Dudullu & 421350 & 14399 \\
15 & 151 & Necip Fazıl & 421400 & 14449 \\
15 & 152 & Necip Fazıl & 421450 & 14499 \\
16 & 161 & Çekmeköy & 421500 & \\
16 & 162 & Çekmeköy & 421550 & \\
\hline & & & & \\
\hline
\end{tabular}

\subsection{SCADA yaptlandermast}

ATS PLC ile SCADA yazılımı arasında hâlihazırda 2 adet veri haberleşmesi mevcuttur. Bunlar; Ray hattının (katener) Güç/Enerji Durumu Bilgisi ve tren tünel içerisinde bölgelerden birinde arıza veya acil bir durumdan dolayı 1 dakikadan fazla kaldığı zaman tüneldeki havalandırma isteğini talep ettiği sıkışık mod senaryosudur. Bu iki durum bilgisi haricinde sistemde herhangi bir bağlantı söz konusu değildir. Tren konum bilgisi ATS sisteminden YBS sistemine gönderilmektedir. YBS sistemine gönderilen aynı bilginin trenin perona 1 dakika kala anons tetiklemesini kullanmak için SCADA sisteminde de kullanılması düşünülmüştür.

ATS PLC üzerinden alınan veriler Modbus TCP/IP haberleşme protokolü ile güvenlik duvarı cihazı üzerinden doğrudan SCADA yazılımına aktarılmalıdır. Arada herhangi bir PLC, Uzak Giriş Çıkış (Remote Input Output - RIO) veya Uzak Kontrol Cihazı (Remote Terminal Unit RTU) gibi bir cihaz bulunmaz. Yazılım olarak Siemens firmasının geliştirmiş olduğu açık mimari özelliği olan WinCC OA yazılımı tercih edilmiştir. Bilgi teknolojisi ve endüstri gibi değişik alanların ihtiyaç duyabileceği bir çok haberleşme sürücüsüne sahip, olay odaklı ve modüler olması sayesinde çok fazla genişleme ve ölçekleme imkanı olan, her işletim sisteminde çalıştırılabilen, hazır modüllerin yanında kodlama ile mevcut modüllerde değişikliğe veya yeni modül eklenmesine imkan tanıyan, yeni ve modern tekniklerin tamamını destekleyen, açık mimariye sahip, hitap ettiği sektörler itibari ile üst seviye bir SCADA yazılımıdır [9]. 
ATS PLC' den alınan verilerin daha önce Modbus TCP/IP haberleşme protokolü üzerinden yapılacağı belirtilmişti. Sistemin tasarımına verinin alınacağı ATS PLC cihazının IP adresinin SCADA yazılımına eklenmesi yapılarak başlanmalıdır. Tanımlama işlemi için Şekil 2' de görseldeki menü çubuklarından SysMgm menüsünden Driver sekmesinden Modbus Driver seçilmelidir. Karşımıza çıkan ekrandan PLC numarası, işlem zaman aşımı süresi, çerçeve kodlama türü (TCP), birim ve IP adres değerleri girilmelidir. Böylece ATS PLC ile senkronizasyon tamamlanıp SCADA sistemi ile karşılıklı veri haberleşmesine olanak sağlanır.

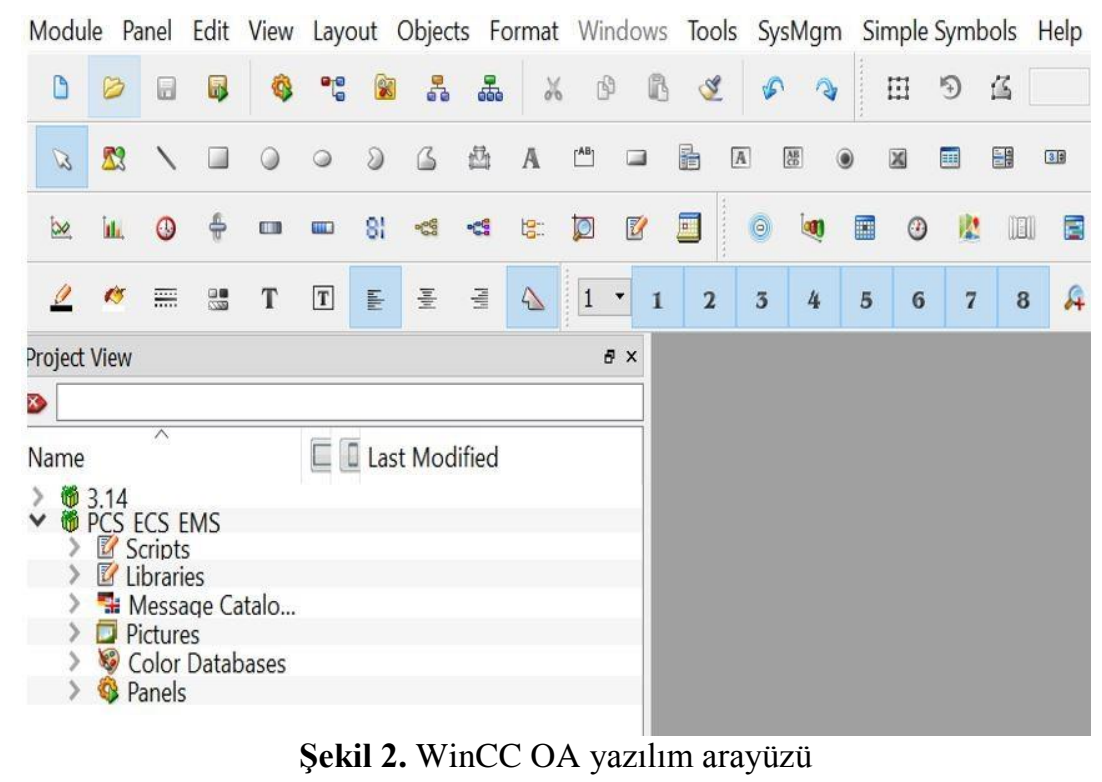

Yapılan işlemler sonucunda SCADA yazılımı WinCC OA ile ATS PLC' nin haberleşmesi sağlanır. Buradan sonraki işlemler artık SCADA yazılımda yapılmalıdır. Sinyalizasyon sistemi tarafinda belirlenmiş olan 3.1.3 ATS - Genel Sistem Durumu, 3.1.4 ATS - Peron Bilgi Durumu ve Adresleri başlıkları altında yer alan tablolardaki Modbus adres değerleri WinCC OA yazılımına eklenmesi gerekmektedir. Şekil 2' deki menü çubuklarından Module menüsünden PARA modülü tıklanarak SCADA sistemiyle haberleşen diğer tüm ekipmanların verilerinin yapılandırmasının yapıldığı ekran karşımıza gelir (Şekil 3).

PARA modülü, veri noktası tiplerini ve veri noktalarını düzenlemek için kullanılan grafiksel bir arayüzdür. Bu arayüz bir araç oluşturur. Araç ile dâhili veri tabanına erişebilir ve aynı anda değişiklik de yapılabilmektedir. Yapısıyla birlikte veri noktası türü, kendisinden türetilen benzer veri noktaları için bir şablon görevi görür.

Veri noktası türleri ve veri noktaları WinCC OA' da birkaç farklı yolla oluşturulabilmekte ve yapılandırılmaktadır. Toplu yapılandırma da yeni veri noktaları oluşturulurken "master data point" adında veri eklemesi yapılıp diğer tüm verilerin bunu referans almasını sağlanabilmektedir. Harici kaynaklardan alınan veriler sisteme aktarmak için Amerikan Standart Bilgi Değişimi Kodu (American Standard Code for Information Interchange - ASCII) dosyalarını kullanmak mümkün olsa da, daha uygun olan seçenek PARA modülüyle çalışmaktır [10]. Şekil 4' de gösterilen panel, Modbus TCP/IP sürücüsü için çevresel adres konfigürasyonuna izin verir. Adresi doğrudan Referans metin alanına girebilir veya döndürme düğmeleriyle (mavi kutucuk) oluşturulur. 


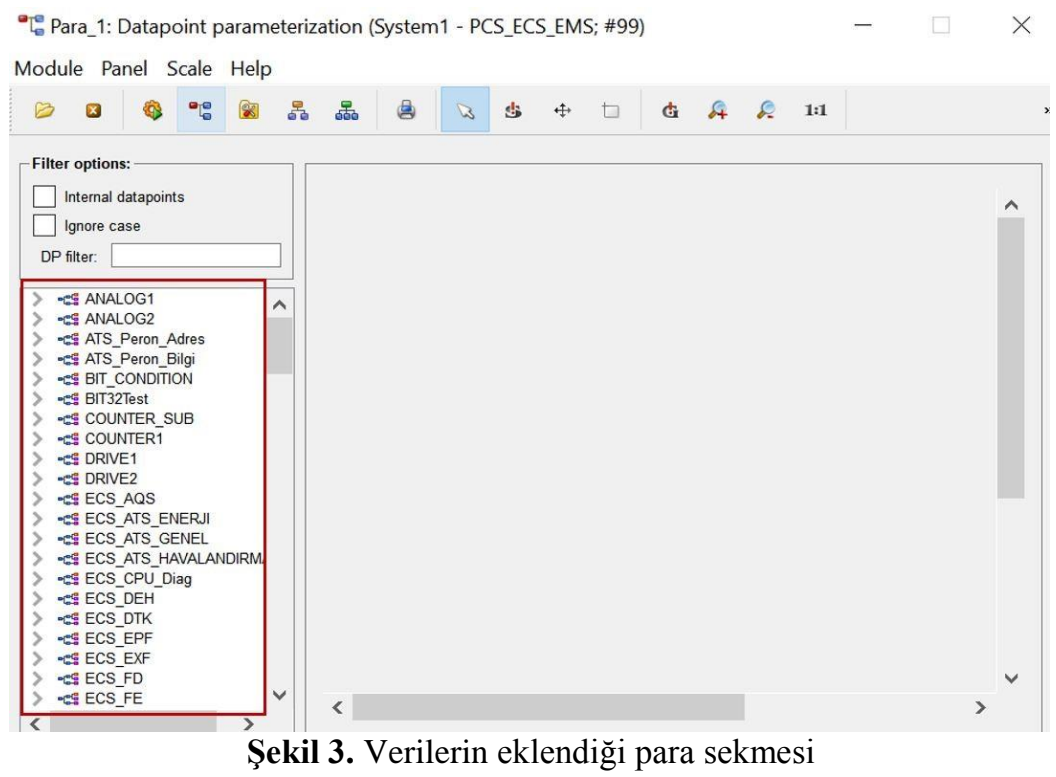

Tablo-2' deki ATS Genel Sistem Durumu başlığı altındaki Modbus adres değerlerini Para sekmesinde oluşturup ECS_ATS_GENEL veri noktası düğümü altındaki ATS_Genel klasörü alt başlıklarındaki Ay, Gün, Yı11, Saat, Dakika, Saniye ve diğer açıklamalarının Modbus değerlerinin adres atamasını Şekil 4' de görüleceği gibi yapılmalıdır.

- $\quad$ Type $=$ Haberleşme tipi Modbus

- $\quad$ PLC Number $=$ SysMgm sekmesi adımında girilen PLC numara değeri

- $\quad \mathrm{FC} / \mathrm{SFC}=$ Olası işlev kodları. Tüm işlev kodları, Modlar ve adres kombinasyonları mümkün değildir. Kullanılan fonksiyon kodu, WinCC OA sürücüsünün bağımlı modundaki PLC' ye bağlıdır.

- Reference Number = ATS PLC' de belirlenmiş olan adres değerleri girilmelidir. Referans numarası, kayıt tabanlı fonksiyon kodları için 16 bit Word (işaretsiz 2 baytlık tam sayı) ve bit tabanlı fonksiyon kodları için bir bit numarası (işaretsiz 2 baytlık tam sayı) içeren bir adrestir.

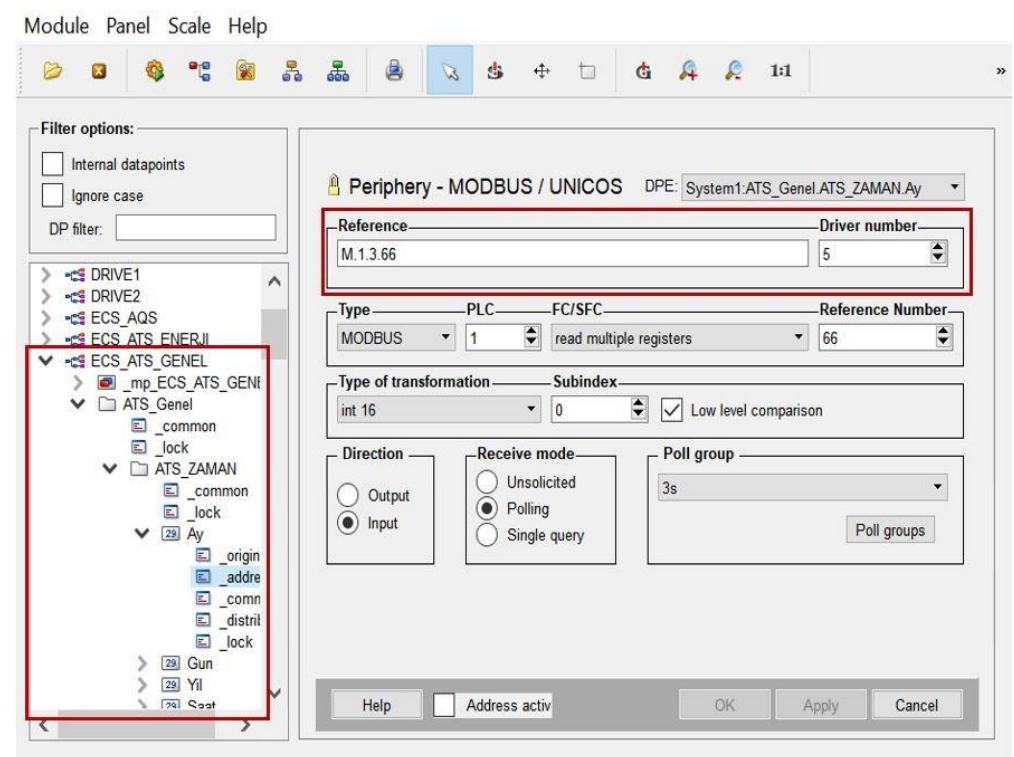

Şekil 4. ATS PLC verilerinin eklenmesi 
Modbus adres değerleri Tablo 2' de yer alan tüm veriler için ECS_ATS_GENEL düğümü altında işlenmelidir. Böylece ATS PLC ile SCADA yazılımı arasındaki sistem durumlarını içeren verilerin haberleşmesi sağlanmıştır.

Bu adımdan sonra yapılması gereken 2 adım kalır. Bunlardan birincisi tıpkı Tablo 2' de yapılan verilerin eklenmesini Tablo-3 ve Tablo-4 içinde gerçekleştirmektir. Tablo-3 ve Tablo-4' de yer alan Peron Bilgi ve Peron Adres değerleri için ECS_ATS_GENEL düğümünde yapılan işlem adımlarının aynısını ATS_Peron_Adres ve ATS_Peron_Bilgi adlarında veri noktası dügümü oluşturarak yapılabilir. Şekil 4' de yer alan işlem adımlarının aynısını bu Modbus adres değeri içinde yapılıp sistem bağlantısı yapılmalıdır.

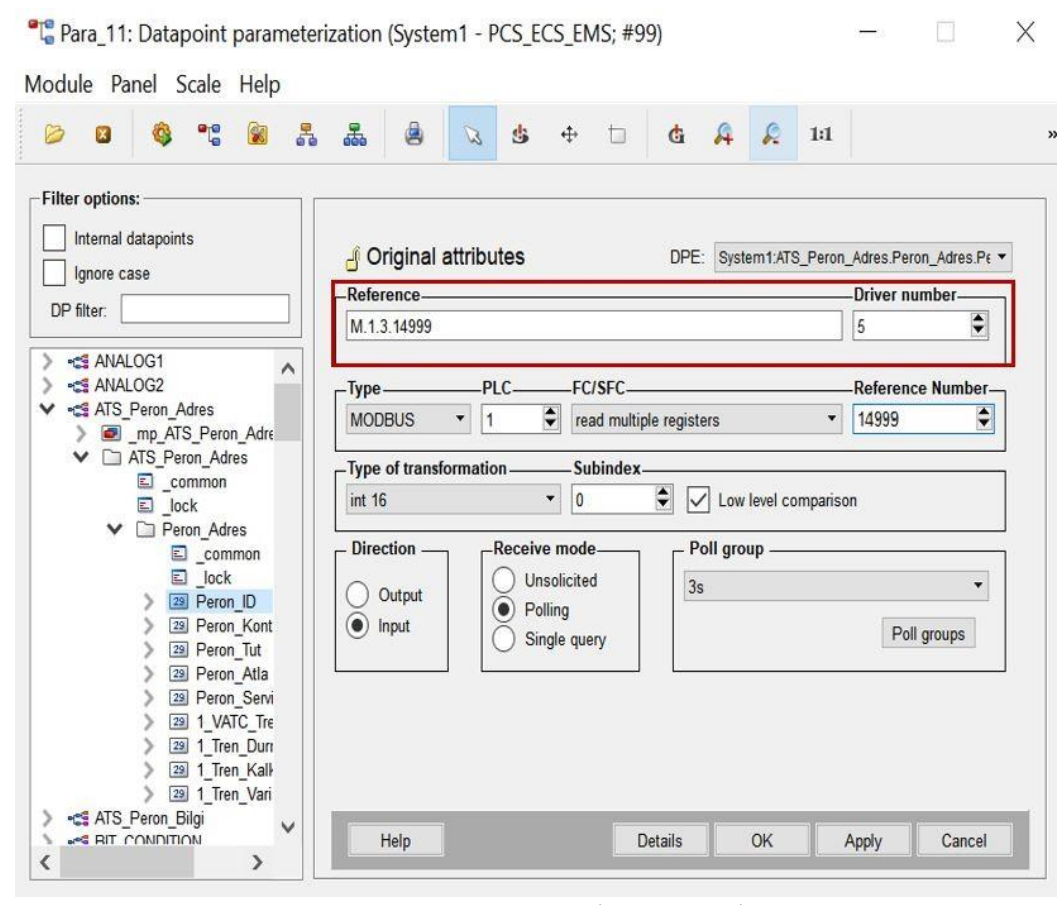

Şekil 5. Peron bilgi adres atamaları

\subsection{Anons yaptlandırmast}

Üçüncü adımda yapılması gereken ise sinyalizasyon sistemiyle ilgili bir adım değildir. Buradaki işlem adımı sahaya gönderilen anonsun SCADA sistemine eklenmesinin sağlanmasıdır. Bunun içinde SCADA sistemi ile anons sistemi arasında saha bağlantısının yapılması gerekiyor. Sahaya gönderilen ilgili anonsun bağlı olduğu fiziksel kablo anons sistemi ekipmanı olan Evrensel Arayüz Modülü (Universal Interface Module - UIM) cihazından, SCADA sisteminin alt sistemi olan RIO panosuna çekilmelidir. Çekilen olan kablonun SCADA alt sistemi RIO' daki ilgili Giriş/Çıkış (Input/Output - IO) kartlardan hangisine montajı yapıldığı bilinirse yazılımda ona göre tanıtma işlemi yapılır.

Sahaya gönderilen anonsun haberleşmesi fiziksel olarak yapılması gerektiği için adres tanımlama işlemi ATS PLC' deki gibi yapılmamaktadır. SCADA sistemine ait PLC' ye anonsun bağlantısının yapılacağı ilgili girişlerin ve çıkışların öncelikle tanımlanması gerekmektedir. $\mathrm{Bu}$ tanımlama işleminde kullanılan adres atama değerlerini daha önce sisteme eklenmiş olan diğer tüm sistemlere ait sinyallerde kullanılan yöntem kullanılmalıdır. Sinyal değerlerinin eklenmesi için Siemens Simatic Manager yazılım programı kullanılmalıdır. Burada yapılan yapılandırma işlemi sonucunda WinCC $\mathrm{OA}$ tarafindaki konfigürasyonun tamamlanıp sahaya gönderilen anonsun sisteme birleşimiyle sağlanmış olunur. 


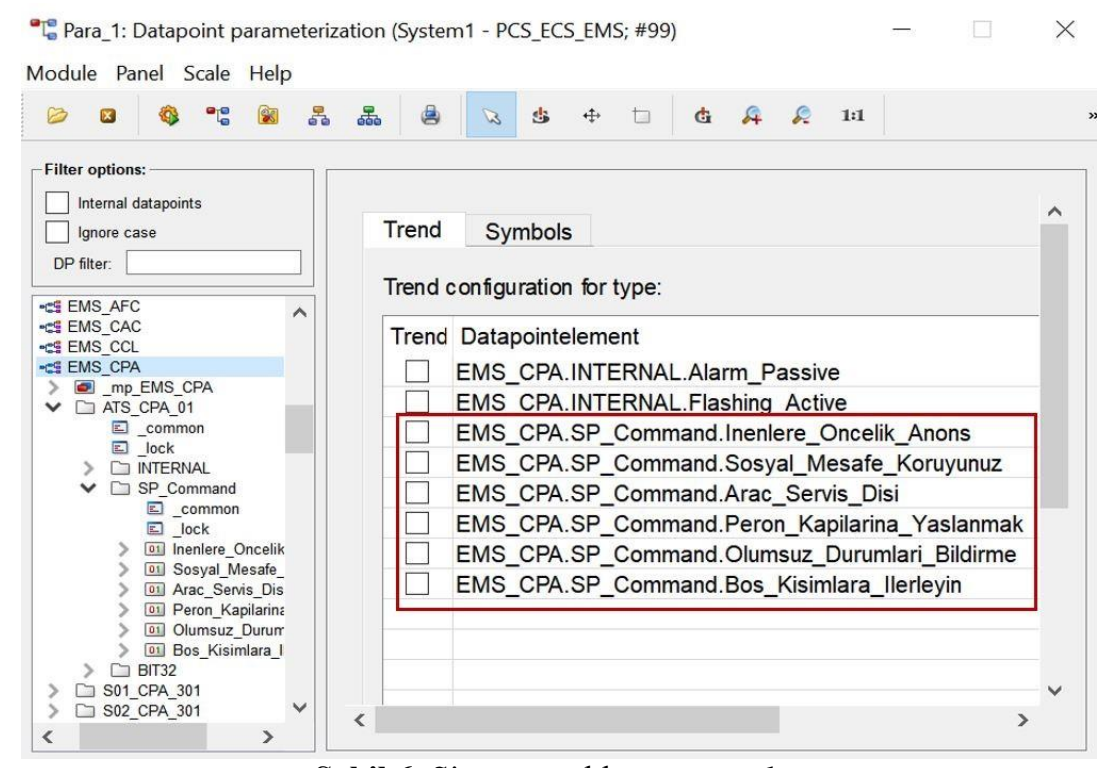

Şekil 6. Sisteme yüklenen anonslar

\section{Sonuç}

Çalışmanın işlem adımları 3 başlık altında anlatılmıştır. Birinci adımda SCADA sistemi tarafından otomatik anons yaptırılmasını sağlamak için sinyalizasyon yapılandırılmasının nasıl olduğunun belirtilmesidir. İkinci adımda sinyal sistemi tarafından belirlenen verilerin SCADA sistemi yazılımı WinCC OA yazılımına Modbus TCP/IP haberleşme protokolü ile birleșimin nasıl yapıldığı gösteren SCADA yapılandırmasıdır. Böylece sinyal sistemi tarafından gönderilen trenin kaç dakikada peronda olacağını bilgisi, trenin servis dışı bilgisi, birbirleri arasındaki haberleşme durumu, peronların ID numaraları, istasyonların her iki peron içinde adres değerleri gibi diğer veriler güvenlik duvarı cihazı üzerinden SCADA sistemine gönderilmesi sağlanır. Üçüncü adımda ise Modbus TCP/IP protokolüyle ATS PLC üzerinden alınan, trenin perona kaç dakikada geleceği bilgisine göre 1 dakika kala otomatik anons yaptırılması için SCADA sistemi ile anons sistemi bağlantısı yapılmasıdır. Fiziksel olarak kablo çekim işi yapıldıktan sonra ilgili yazılım konfigürasyonu eklemesiyle trenin perona girmesine 1 dakika kala yapılan tasarımın sonucunda otomatik anons yaptırilır.

Bu çalışmanın faaliyete geçmesiyle birlikte M5 Üsküdar-Ümraniye-Çekmeköy sürücüsüz metro hattının yoğun yolcu saatlerinde veya dışında yaşanan trenden inen ve binen yolcu arasındaki kargaşanın önlenmesi, birbirlerine karşı hakların korunmasının sağlanması ve son zamanlarda yaşanılan Covid-19 salgın hastalığındaki sosyal mesafenin korunması adına yapılan bu işlemler önemli bir farkındalık çalışmasıdır. Trenden inen ve binen yolcuların birbirlerine karşı tolerans göstermemesi sonucunda yolcular arasında sözlü veya fiziki münakaşa yaşanabilir. Yaşanılan bu arbede kimi zaman tren içerisinde kimi zamanda peron bölgesinde devam etmektedir. Bunun sonucunda araç içinde maddi hasar, sefer aksaması, seyahat eden diğer yolcuların çevresel rahatsızlığı gibi durumlar oluşur. Modern şehircilik kültürünü ilke edinmiş ve kesintisiz ulaşım adına her geçen gün adımlar adan Metro İstanbul AŞ' de bu durum kabul edilemez bir husustur. $\mathrm{Bu}$ sebeple hem metro kültürünü tüm şehre yayılması, hem konforlu ulaşımı en üst noktaya çıkarılması, hem de yolcuların birbirlerine karşı haklarının nasıl olması gerektiği dair önemli bir çalışmadır. Sistem altyapısının oluşturulmasıyla birlikte son dönemde yaşanılan salgın hastalığındaki sosyal mesafenin korunması gerekliliği, temizlik ve hijyenin önemi, maske takılma zorunluluğu, seyahat halinde iken yiyecek-içecek tüketilmesini sonucunda doğabilecek damlacıkların diğer yolculara vereceği zararların yolculara duyurulması sağlanmaktadır. 
Sağlanan bu hizmetler sonucunda işletmeci firma olarak seyahat eden yolculardan olumlu geri dönüşler alınmaktadır.

\section{Teşekkür}

$\mathrm{Bu}$ çalışmada kullanılan verilerin kullanımı ve destekleri için Metro İstanbul A.Ş. Elektronik Sistemler Bakım Müdürlügü̆' ne teşekkür ederiz.

\section{Kaynakça}

[1] E. Çekerek, İ. Kandilli ve M. Kuncan, "Yeraltı metro hatlarında video analiz yöntemiyle olay algılama kontrolünün gerçekleştirilmesi," El-Cezeri Journal of Science and Engineering, pp 1025-1038, 2020.

[2] J. Stover, "CITYFLO 650 system overview," Bombardier Company, 2006.

[3] O. İlhan, "Raylı Ulaşımda Sinyalizasyon Sistemlerinin Analizi ve Kadıköy - Kartal Metrosu İçin Sinyalizasyon Sistemi Uygulamaları," Yüksek lisans tezi, Gebze Teknik Üniversitesi, Fen Bilimleri Enstitüsü, Kocaeli, 2011.

[4] B. Hunyadi ve A. Cano, "Architecture description for the signaling system," Alstom - Bombardier Transportation, 2016.

[5] Sandia National Labs, "The center for SCADA security," 2007.

[6] Á. Esteban, "Data transmission system," Alstom - Bombardier Transportation, 2016.

[7] HUBBOX Endüstriyel Teknoloji, What are MODBUS Protocol and all its features? https://www.hubbox.io/en/blog/data-collect/modbus-protokolu-ve-tum-ozellikleri-nedir. [Accessed November 1, 2020].

[8] D.Planells, "ICD external interfaces: ATS-Platform PIS," Alstom - Bombardier Transportation, 2016.

[9] Elmak Kontrol Sistemleri, "M5 UUCM - SCADA bakım kılavuzu," 2020.

[10] Siemens Automation Systems, "WinCC OA online help," 2020.
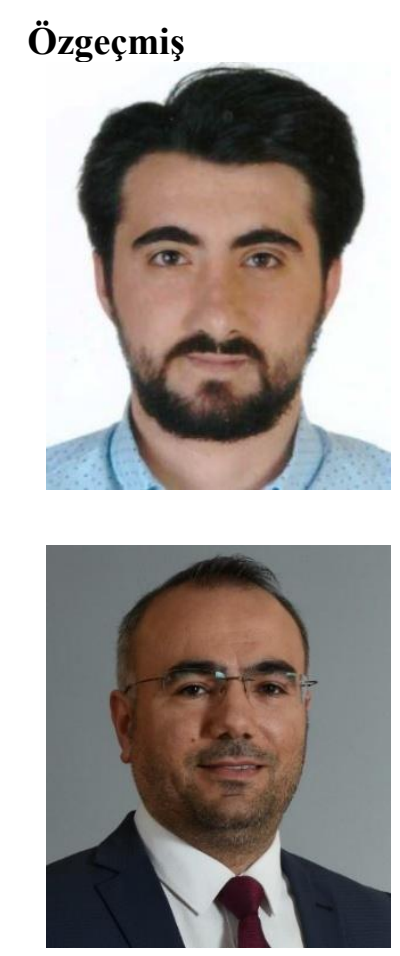

\section{Beyanlar:}

Bu makalede bilimsel araştırma ve yayın etiğine uyulmuştur.

Tüm yazarların eşit oranda katkısı olmuştur.

\section{Emre ÇEKEREK}

Lisans öğrenimini Samsun Ondokuz Mayıs Üniversitesi ElektrikElektronik Mühendisliği bölümünde tamamlamıştır. Kocaeli Üniversitesi Elektronik ve Haberleşme Mühendisliği bölümünde Yüksek Lisans öğrenimine devam etmektedir. 2018 y1lında İBB Metro İstanbul AŞ'de Elektrik-Elektronik Mühendisi olarak işe başlamış olup M5 Üsküdar-Ümraniye-Çekmeköy sürücüsüz metro hattında Sinyalizasyon ve SCADA sistemlerinden sorumlu mühendis olarak çalışmaktadır.

E-Posta: emrecekerek@gmail.com

\section{Mehmet DEMIR}

Lisans öğrenimini Gebze Yüksek Teknolojisi Enstitüsü Elektronik Mühendisliği bölümünde tamamlamıştır. Yüksek Lisans eğitimini 2014 yılında Yıldız Teknik Üniversitesi Elektronik ve Haberleşme Mühendisliği bölümünde bitirerek Yüksek Mühendis unvanını almıştır. 2011 yılında İBB Metro İstanbul AŞ'de sırasıyla Sinyalizasyon Mühendisi, Sinyalizasyon ve Kontrol \& Haberleşme sistemlerinden sorumlu Elektronik Şefi olarak görev yapmıştır. Halen aynı firmada Müşavirlik Hizmetleri Müdürü olarak görevine devam etmektedir.

E-Posta: mehmet.demir@metro.istanbul 